\title{
Retinopathy among type 2 diabetic patients seen at a tertiary hospital in Nigeria: a preliminary report
}

\author{
Adeyinka Ashaye' \\ Ayodeji Arije ${ }^{2}$ \\ Modupe Kuti ${ }^{3}$ \\ Bolutife Olusanya' \\ Ezekiel Ayeni' \\ Adesoji Fasanmade ${ }^{4}$ \\ Kehinde Akinlade ${ }^{3}$ \\ Millicent Obajimi ${ }^{5}$ \\ Jokotade Adeleye ${ }^{4}$ \\ 'Ophthalmology Department, College \\ of Medicine, University of Ibadan, \\ Nigeria; ${ }^{2}$ Renal Unit, Department \\ of Medicine, College of Medicine, \\ University of Ibadan, Nigeria; \\ ${ }^{3}$ Department of Chemical Pathology, \\ College of Medicine, University of \\ Ibadan, Nigeria; ${ }^{4}$ Endocrine Unit, \\ Department of Medicine, College \\ of Medicine, University of Ibadan, \\ Nigeria; ${ }^{5}$ Radiology Department, \\ College of Medicine, University of \\ lbadan, Nigeria
}

\begin{abstract}
Objective: To determine the prevalence of diabetic retinopathy among patients attending the diabetic clinics of a tertiary hospital in Nigeria.

Methodology: We examined the eyes of 76 patients with type 2 diabetes mellitus between July 2003 and January 2004 using dilated fundoscopy at the eye clinic of the University College Hospital, Ibadan. The results were compared with published figures.

Results: Mean age of patients was $57.5 \pm 10.4$ years. Thirty-two patients $(42.1 \%)$ had diabetic retinopathy. Of these, one patient had features of proliferative diabetic retinopathy while the other patients had non-proliferative diabetic retinopathy. Majority $(53.1 \%)$ of those who had retinopathy had diabetes for more than 10 years, while $21.4 \%$ of patients without retinopathy had diabetes for more than 10 years $(\mathrm{p}=0.005)$. The mean serial post-prandial plasma glucose of those who had retinopathy was higher when compared with the mean for those who did not have retinopathy $(248.7 \mathrm{mg} / \mathrm{dl}$ vs $178.3 \mathrm{mg} / \mathrm{dl} ; \mathrm{p}=0.003)$.

Conclusion: The prevalence of diabetic retinopathy in our patients is higher than was previously reported in earlier studies. Patients with diabetes ought to be referred for ophthalmological evaluation and follow-up which they should be actively encouraged to attend.

Keywords: diabetic retinopathy, tertiary hospital patients, Africans
\end{abstract}

\section{Introduction}

Diabetes mellitus is an important health problem worldwide. In Africans, there has been a progressive increase in the prevalence of diabetes mellitus and the burden is expected to increase even further (Adeleye et al 2006). Due to the high urban growth rate, dietary changes, reduction in physical activity, and increasing incidence of obesity, it is estimated that the prevalence of diabetes may triple within the next 25 years (Sobngwi et al 2001).

Diabetic retinopathy is the leading cause of blindness in adults between the ages of 20 and 65 in industrialized countries (Rotimi et al 2003). It is said to account for $12 \%$ of new cases of blindness in the USA (Patz and Smith 1991; Moss et al 1998 ) and $11.9 \%$ of all blind registration in those aged 16-64 years in the United Kingdom (Evans et al 1996). Population based surveys in developed countries have reported the presence of retinopathy in about a third of adults with diabetes; $36.8 \%$ (Klein et al 1992a), 32.4\% (Mitchell et al 1998). Over thirty years ago, diabetic retinopathy was reported to be rare in Nigerians (Osuntokun 1969; Abiose 1978). But more recent studies have shown that the occurrence of diabetic retinopathy in Nigeria is on the increase (Erasmus et al 1989), and that it accounts for $16.7 \%$ of all retinal diseases (Nwosu 2000). Other studies report prevalence rates between 15\% and 38\% among clinic attending diabetics patients in Sub Saharan Africa (Erasmus et al 1989; Kalk et al 1997; Ndiaye et al 1999; Nwosu 2000; Seyoum et al 2001; Rotimi et al 2003). 
Certain factors have been well documented as being significantly associated with an increased risk of development and/or worsening of diabetic retinopathy. These include duration of diabetes (Klein et al 1992b), age (Krakoff et al 2003), female sex (Sparrow 1993), poor blood sugar control ie, hyperglycemia (Stratton et al 2001), elevated blood pressure (Matthews et al 2004), hyperlipidemia (Viswanath 2003), diabetic nephropathy (El-Asrar et al 2001; Trevisan et al 2002; Alebiosu et al 2003) and obesity (Van Leiden et al 2002; Katusic et al 2005).

Racial differences in the risk of developing retinopathy exist among individuals with type 2 diabetes (Harris et al 1998; Leske et al 1999). These differences may be due to increased risk of diabetes in the black population (Harris 1991; Cooper et al 1997) or increased prevalence of risk factors for diabetic retinopathy among black patients or a greater impact of identified risk factors for diabetic retinopathy among them.

Differences in the prevalence of diabetic retinopathy between African Americans and whites have been explained by differences in diabetic severity, glycaemic control and presence of elevated blood pressure (Harris et al 1998; Leske et al 1999). Longitudinal studies are needed to address these issues; and data presented will be useful to establish prevention in the high risk groups. West Africans who share the same ancestry origin as African Americans are such high risk groups. This pilot study was conducted to provide estimates for use in sample size calculations in subsequent work. The study was a collaborated study of patients with type 2 diabetes mellitus conducted with the aim of investigating the laboratory and clinical parameters of diabetes as well as to determine the prevalence of diabetic retinopathy among new patients attending the diabetic clinics of the hospital.

\section{Patients and methods}

The study population was drawn from the adults with diabetes who attended the diabetic clinic of the University College Hospital (UCH), Ibadan.

All consecutive new patients with type 2 diabetes seen at the diabetic clinic between July 2003 and January 2004 were referred to the eye clinic of the same hospital. Patients were classified as having type 2 diabetes mellitus if they did not require insulin to achieve glycaemic control within the first 3 months of diagnosis as well as if they were older than 20 years of age.

Retinopathy status was assessed using dilated ophthalmoscopy by an experienced ophthalmologist who had no prior knowledge of the clinical characteristics of the patients, thereby eliminating clinical potential sources of bias. No fundus photography was available at the time of the study.

Information was obtained with the use of a structured questionnaire. Other data collected included demographic data, history of co-morbid illness, complications of diabetes, and compliance with current medication. Investigations performed at the diabetic clinic included serial monthly fasting plasma glucose and two hour post-prandial plasma glucose, urinalysis, Glomerular filtration rate estimation, and renal ultrasound scan. In the absence of facilities for measurement of Hemoglobin A1c, which is a better indicator of glucose control over time, all plasma glucose results of the preceding three to six months of all subjects were averaged. All estimations were carried out in the central laboratory of the hospital. This variable gave a fairly accurate indication of the level of control of plasma glucose in these patients.

Ocular examination comprised of refraction, pen torch and slit lamp examination as well as dilated fundoscopy with the use of 78D Volk lens. A diagnosis of diabetic retinopathy was made only where a participant had a minimum of one microaneurysm in any field, as well as exhibiting hemorrhages (dot, blot, or flame shaped), and maculopathy (with or without clinically significant edema). Proliferative diabetic retinopathy was diagnosed when there was neovascularisation. The criteria used to classify patients into categories of diabetic retinopathy was based on the criteria of the Diabetic Retinopathy Study (DRS Report 7 1981) and Early Treatment Diabetic Retinopathy Study (ETDRS Report 10 1991).

Approval for the study protocol was obtained from the Institutional Ethical Review Board of the College of Medicine, University of Ibadan. Informed consent was obtained from each participant at the clinic.

Data collected at both the diabetic clinic and the eye clinic was analyzed using SPSS version 11 software. Statistical significance was $\mathrm{p}<0.05$.

Although both eyes were examined, the eye with the more severe retinopathy was used for analysis.

\section{Results}

Out of the 133 patients recruited into study at the diabetic clinics, 76 patients $(57.1 \%)$ presented at the eye clinic for ocular examination. These 76 patients were studied.

There were 37 males and 39 females (male to female ratio -0.95 ). Their ages ranged between 33 and 82 years with a mean of $57.5 \pm 10.4$ years.

Duration since diagnosis of diabetes mellitus ranged from three months to 30 years with a mean of $8.6 \pm 7.6$ years. 
Forty-seven patients $(61.8 \%)$ were on treatment for hypertension.

Therapy for control of diabetes was by dietary control in 1 patient (1.3\%); the use of oral hypoglycaemic agents in 68 patients $(89.5 \%)$ and insulin in 7 patients $(9.2 \%)$.

The clinical and laboratory characteristics of those who participated in the ocular assessment were similar to those who did not turn up for examination.

Males constituted $48.7 \%$ of participants compared with $56.1 \%$ of non-participants $(\mathrm{p}=0.3)$. The mean age of participants was 57.5 years compared with 56.1 years for nonparticipants $(\mathrm{p}=0.5)$. The comparison of the characteristics of the two groups is shown in Table 1.

Two of the patients examined at the eye clinic were found to have bilateral lens opacities dense enough to prevent a satisfactory view of the posterior pole and therefore a definite statement on the presence or absence of retinopathy could not be made. These two patients were not included in further analysis.

Of the remaining 74 patients, $32(42.1 \%)$ had diabetic retinopathy. One $(3.1 \%)$ of these patients had features of proliferative diabetic retinopathy while 31 patients $(96.9 \%)$ had non-proliferative diabetic retinopathy.

The mean age of patients with retinopathy was higher than the mean age of those patients without retinopathy ( 57.8 years vs 56.9 years; $p=0.7$ ). The mean duration since diagnosis (of diabetes) in patients who had retinopathy was longer than the mean for those without retinopathy (11.1 years vs 6.6 years; $p=0.01)$. The mean post-prandial plasma glucose (calculated from three to six months of serial monitoring) of those who had retinopathy was higher when compared with the mean for those who did not have retinopathy $(248.7 \mathrm{mg} / \mathrm{dl}$ vs $178.3 \mathrm{mg} / \mathrm{dl} ; \mathrm{p}=0.003$ ). Table 2 shows the comparison of the mean values of the various parameters studied in the two groups of patients.

Further analysis revealed that $74.2 \%$ of those with retinopathy were older than 50 years, compared to $64.3 \%$ of the patients without retinopathy that were older than 50 years $(p=0.37)$. Females made up $56.3 \%$ of those with retinopathy compared to $50 \%$ of those without retinopathy $(\mathrm{p}=0.6)$.

Majority (53.1\%) of the patients with retinopathy had diabetes for more than 10 years, compared to $21.4 \%$ of those without retinopathy $(\mathrm{p}=0.005$; Odds ratio $=2.5 ; 95 \%$ Confidence Interval $=1.3-4.8$ ).

A larger proportion of those with diabetic retinopathy had poor glycemic control ie, post-prandial plasma glucose greater than $200 \mathrm{mg} / \mathrm{dl}$ in comparison with those without retinopathy $(58.3 \%$ vs $27.0 \% ; \mathrm{p}=0.014$; Odds ratio $=2.2$; $95 \%$ Confidence interval $=1.2-4.0$ ).

In addition, $18.8 \%$ of those with retinopathy were on insulin therapy while $2.4 \%$ of those without retinopathy were on insulin $(\mathrm{p}=0.02$; Odds ratio $=7.7 ; 95 \%$ confidence interval $=0.97-60.7)$ Table 3 shows other factors that were compared between the two groups.

\section{Discussion}

The response rate of the patients referred for ophthalmological examination was poor with only $57 \%$ of the patients actually presenting to the eye clinic. This is a manifestation of the lack of importance attached to routine eye examinations by diabetic patients seen at UCH Ibadan. Adequate health education for newly diagnosed diabetic patients is imperative in order to emphasize the need for regular eye examinations.

The patients who were examined do not differ from those who did not participate with respect to the major

Table I Characteristics by participation status

\begin{tabular}{|c|c|c|c|}
\hline & Participants & Non-participants & p value \\
\hline$n$ & 76 & 57 & - \\
\hline Male sex (\%) & 48.7 & 56.1 & 0.3 \\
\hline Mean age (years) & $57.5( \pm 10.4)$ & $56.1( \pm 14.3)$ & 0.5 \\
\hline Mean duration (years) & $8.6( \pm 7.6)$ & 8. I $( \pm 7.2)$ & 0.7 \\
\hline Insulin therapy (\%) & 9.3 & 19.3 & 0.1 \\
\hline Mean serial plasma glucose $(\mathrm{mg} / \mathrm{dL})$ & $207.4( \pm 93.0)$ & $189.2( \pm 70.0)$ & 0.2 \\
\hline Mean body mass index $\left(\mathrm{kg} / \mathrm{m}^{2}\right)$ & $25.99( \pm 4.8)$ & $25.85( \pm 4.3)$ & 0.9 \\
\hline Mean systolic blood pressure $(\mathrm{mmHg})$ & $137.2( \pm 20.8)$ & $135.2( \pm 27.8)$ & 0.7 \\
\hline Mean diastolic blood pressure $(\mathrm{mmHg})$ & $82.8( \pm 12.1)$ & $82.0( \pm 11.8)$ & 0.7 \\
\hline Presence of albuminuria (\%) & 28.6 & 48.6 & 0.07 \\
\hline Mean estimated GFR ${ }^{a}(\mathrm{~mL} / \mathrm{min})$ & $82.2( \pm 23.6)$ & $79.6( \pm 28.4)$ & 0.6 \\
\hline
\end{tabular}

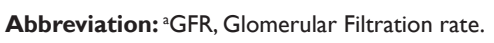


Table 2 Study factors by retinopathy status

\begin{tabular}{llll}
\hline & No retinopathy & Have retinopathy & P value \\
\hline $\mathrm{N}$ & 42 & 32 & 0.7 \\
Mean age (years) & $56.9( \pm 10.8)$ & $57.8( \pm 9.8)$ & $0.0 \mathrm{I}$ \\
Mean duration (years) & $6.6( \pm 6.8)$ & $1 \mathrm{I} . \mathrm{I}( \pm 8.1)$ & 0.003 \\
Mean serial plasma glucose $(\mathrm{mg} / \mathrm{dL})$ & $178.3( \pm 83.9)$ & $248.7( \pm 88.7)$ & 0.9 \\
Mean body mass index $\left(\mathrm{kg} / \mathrm{m}^{2}\right)$ & $26.1( \pm 4.5)$ & $25.9( \pm 5.2)$ & 0.7 \\
Mean systolic blood pressure $(\mathrm{mmHg})$ & $136.2( \pm 18.3)$ & $138.5( \pm 23.9)$ & 0.23 \\
Mean diastolic blood pressure $(\mathrm{mmHg})$ & $82.1( \pm 10.4)$ & $84.6( \pm 14.0)$ & 0.32 \\
Mean estimated GFR $(\mathrm{mL} / \mathrm{min})$ & $86.4( \pm 38.4)$ & $76.8( \pm 26.4)$ & \\
\hline
\end{tabular}

Abbreviation: ${ }^{\mathrm{a} G F R}$, Glomerular Filtration rate.

study parameters. Although the proportion of females, patients on insulin therapy and those who had albuminuria as well as the mean serial post-prandial plasma glucose was higher in the participants group, there was no statistically significant difference. Hence the possibility of selection bias is minimized and is not likely to account for the poor response rate observed.

The prevalence of diabetic retinopathy among these patients $(42.1 \%)$ is higher than has been reported elsewhere in Nigeria and West Africa. Erasmus et al (1989) reported a prevalence of $15.1 \%$ among the 377 diabetic patients they studied in a Nigerian Teaching Hospital, while Rotimi et al (2003) working on a group of 840 diabetic patients in Nigerian and Ghanian tertiary hospitals reported that $17.9 \%$ of them had retinopathy. Thus, it may be postulated that the prevalence of retinopathy among diabetics in Nigeria is on the increase however the difference in number of patients studied may be responsible for the higher prevalence recorded in this study. Another factor that may account for the differences in prevalence is the variation in criteria for defining the presence of diabetic retinopathy between different studies. In addition, variations in the examiners (ophthalmologist vs non-ophthalmologist) as well as the examination methods (direct vs indirect ophthalmoloscopy) should be considered. The use of the Volk lens increases the sensitivity of fundoscopy in diagnosis of retinal lesions.

The duration of diabetes was significantly associated with the presence of diabetic retinopathy. This risk factor has been described as the most important and strongest risk factor associated with development of diabetic retinopathy (Klein et al 1992b). We found that those patients who had the disease for more than 10 years since diagnosis were two and a half times more likely to have diabetic retinopathy than those whose disease was diagnosed less than 10 years previously. This finding is in concordance with various studies that have established the fact that longer duration of diabetes increases the risk of microvascular complications (Klein et al 1992b; Porta et al 2002; Williams et al 2004).

Elevated mean serial post-prandial plasma glucose level was also significantly associated with an increased risk of having retinopathy in the patients we studied. Our finding simply corroborates a well established fact that poor control of hyperglycemia increases the risk of development and progression of the complications of diabetes mellitus including retinopathy (Stratton et al 2001; Schellhase et al 2005).

Table 3 Study factors by retinopathy status

\begin{tabular}{llll}
\hline & No retinopathy & Have retinopathy & P value \\
\hline $\mathrm{N}$ & 42 & 32 & 0.37 \\
Age $>50$ yrs & $64.3 \%$ & $74.2 \%$ & 0.6 \\
Female sex & $50 \%$ & $56.3 \%$ & 0.005 \\
Duration $>10$ yrs & $21.4 \%$ & $53.1 \%$ & 0.02 \\
Insulin therapy & $2.4 \%$ & $18.8 \%$ & 0.014 \\
Mean serial plasma glucose $>200 \mathrm{mg} / \mathrm{dl}$ & $27.0 \%$ & $58.3 \%$ & 0.4 \\
Body mass index $>25 \mathrm{~kg} / \mathrm{m}^{2}$ & $59.5 \%$ & $48.4 \%$ & 0.6 \\
Systolic blood pressure $>130 \mathrm{mmHg}$ & $51.3 \%$ & $58.1 \%$ & 0.1 \\
Diastolic blood pressure $>80 \mathrm{mmHg}$ & $43.6 \%$ & $61.3 \%$ & 0.5 \\
Presence of albuminuria & $31.3 \%$ & $20.0 \%$ & 0.95 \\
Estimated GFR $260 \mathrm{~mL} / \mathrm{min}$ & $43.8 \%$ & $43.8 \%$ & \\
\hline
\end{tabular}

Abbreviation: ${ }^{\mathrm{a} G F R}$, Glomerular Filtration rate. 
We also found that the type of medication used significantly influenced the risk of diabetic retinopathy in the patients studied. Specifically, the use of insulin was associated with a seven-fold increase in the risk of having retinopathy.

A reason for this finding which has also been reported in other studies (Klein 1987) is that use of insulin therapy in Type 2 diabetics is an indication of severity of the disease. And it is well established that the risk of retinopathy is higher in patients with more severe diabetes mellitus. However, making any conclusion from this finding is limited by the small number of patients on insulin therapy.

Other factors studied were found not to be significantly associated with occurrence of retinopathy. These include age, body mass index, blood pressure, albuminuria, and estimated GFR values. These factors, especially albuminuria and decreased GFR which are related to diabetic nephropathy have been well established as being associated with the risk of retinopathy (Trevisan et al 2002). However, our observation may be due to the relatively small number of patients studied which is one of the limitations of the study.

Other limitations of the study include the poor response rate, the lack of Hemoglobin A1c measurements and the lack of fundus photography.

In conclusion, the prevalence of diabetic retinopathy in our patients is higher than was previously reported in earlier studies. Patients' awareness of the need for eye examination appears low and as such newly diagnosed diabetics should be encouraged to attend regular ophthalmological examinations to enable early detection and treatment of retinopathy as well as other microvascular complications of diabetes especially diabetic nephropathy. This intervention is important preliminary to further studies.

\section{References}

Abiose A. 1978. Retinal diseases in Nigeria - a preliminary report. Niger Med J, 6:180-3.

Adeleye JO, Agada NO, Balogun WO, et al. 2006. Diabetes care in Nigeria: time for a paradigm shift. Afr J Med Med Sci, 35:155-9.

Alebiosu CO, Odusan O, Jaiyesimi A. 2003. Morbidity in relation to stage of diabetic nephropathy in type-2 diabetic patients. J Natl Med Assoc, 95:1042-7.

Cooper RS, Rotimi CN, Kaufman JS, et al. 1997. Prevalence of NIDDM among populations of the African Diaspora. Diabetes Care, 20:343-8.

Diabetic Retinopathy Study Research Group. 1981. A modification of the Airlie House Classification of Diabetic Retinopathy Report 7. Invest Ophthalmol Vis Sci, 21:210-26.

Early Treatment Diabetic Retinopathy Study Research Group. 1991. Grading diabetic retinopathy from stereoscopic color fundus photographs - an extension of the modified Airlie House Classification. ETDRS Report Number 10. Ophthalmology, 98:807-22.
El-Asrar AM, Al-Rubeaan KA, Al-Amro SA, et al. 2001. Retinopathy as a predictor of other diabetic complications. Int Opthalmol, $24: 1-11$.

Erasmus RT, Alanamu RA, Bojuwoye B, et al. 1989. Diabetic retinopathy in Nigerians: relation to duration of diabetes, type of treatment and degree of control. East Afr Med J, 66:248-54.

Evans J, Rooney C, Ashwood F, et al. 1996. Blindness and partial sight in England and Wales: April 1990-March 1991. Health Trends, 28:5-12.

Harris MI. 1991. Epidemiological correlates of NIDDM in Hispanics, whites, and blacks in the U.S. population. Diabetes Care, 14:639-48.

Harris MI, Klein R, Cowie CC, et al. 1998. Is the risk of diabetic retinopathy greater in non-Hispanic blacks and Mexican Americans than in nonHispanic whites with type 2 diabetes? A U.S. population study. Diabetes Care, 21:1230-5.

Kalk WJ, Joannou J, Ntsepo S, et al. 1997. Ethnic differences in the clinical and laboratory associations with retinopathy in adult onset diabetes: studies in patients of African, European and Indian origins. $J$ Intern Med, 241:31-7.

Katusic D, Tomic M, Jukic T, et al. 2005. Obesity - a risk factor for diabetic retinopathy in type 2 diabetes?. Coll Antropol, 29 (Suppl 1):47-50.

Klein R. 1987. The epidemiology of diabetic retinopathy: findings from the Wisconsin Epidemiologic Study of Diabetic Retinopathy. Int Ophthalmol Clin, 27:230-8.

Klein R, Klein BEK, Moss SE, et al. 1992a. The Beaver Dam Eye Study. Retinopathy in adults with newly discovered and previously diagnosed diabetes mellitus. Ophthalmology, 99:58-62.

Klein R, Klein BE, Moss SE. 1992b. Epidemiology of proliferative diabetic retinopathy. Diabetes Care, 15:1875-91.

Krakoff J, Lindsay RS, Looker HC, et al. 2003. Incidence of retinopathy and nephropathy in youth-onset compared with adult-onset type 2 diabetes. Diabetes Care, 26:76-81.

Leske MC, Wu SY, Hyman L. 1999. Diabetic retinopathy in a black population:the Barbados Eye Study. Ophthalmology, 106:1893-9.

Matthews DR, Stratton IM, Aldington SJ, et al. 2004. UK Prospective Diabetes Study Group Risks of progression of retinopathy and vision loss related to tight blood pressure control in type 2 diabetes mellitus: UKPDS 69. Arch Ophthalmol, 122:1631-40.

Mitchell P, Smith W, Wang JJ, et al. 1998. Prevalence of diabetic retinopathy in an older communityThe Blue Mountains Eye Study. Ophthalmology, 105:406-11.

Moss SE, Klien R, Klien BEK. 1998. The 14 year incidence of visual loss in a diabetic population. Ophthalmology, 105:998-1003.

Ndiaye MR, Cisse A, De Medeiros M, et al. 1999. Prevalence of diabetic retinopathy at the Dakar University Hospital Center. Dakar Med, 44:158-61.

Nwosu SNN. 2000. Prevalence and pattern of retinal disease at the Guinness Eye Hospital, Onitsha, Nigeria. Ophthalmic Epidemiol, 7:41-8.

Osuntokun BO. 1969. Diabetic retinopathy in Nigerians. Br J Ophthalmol, $53: 652$.

Patz A, Smith RE. 1991. The ETDRS and Diabetes 2000 (Editorial). Ophthalmology, 98:739-40.

Porta M, Bandello F. 2002. Diabetic retinopathy A clinical update. Diabetologia, 45:1617-34.

Rotimi C, Daniel H, Zhou J, et al. 2003. Prevalence and determinants of diabetic retinopathy and cataracts in West African type 2 diabetes patients. Ethn Dis, 13(2 Suppl 2):S110-7.

Schellhase KG, Koepsell TD, Weiss NS. 2005. Glycemic control and the risk of multiple microvascular diabetic complications. Fam Med, 37:125-30.

Seyoum B, Mengistu Z, Berhanu P, et al. 2001. Retinopathy in patients of Tikur Anbessa Hospital diabetic clinic. Ethiop Med J, 39:123-31.

Sobngwi E, Mauvais-Jarvis F, Vexiau P, et al. 2001. Diabetes in Africans. Part 1: Epidemiology and clinical specifications. Diabetes Metab, $27: 628-34$. 
Sparrow JM, McLeod BK, Smith TD, et al. 1993. The prevalence of diabetic retinopathy and maculopathy and their risk factors in the noninsulintreated diabetic patients of an English town. Eye, 7:158-63.

Stratton IM, Kohner EM, Aldington SJ, et al. 2001. UKPDS 50: risk factors for incidence and progression of retinopathy in Type II diabetes over 6 years from diagnosis. Diabetologia, 44:156-63.

Trevisan R, Vedovato M, Mazzon C, et al. 2002. Concomitance of diabetic retinopathy and proteinuria accelerates the rate of decline of kidney function in type 2 diabetic patients. Diabetes Care, 25:2026-31.
Van Leiden HA, Dekker JM, Moll AC. 2002. Blood pressure, lipids and obesity are associated with retinopathy: the horn study. Diabetes Care, 25:1320-5.

Viswanath K, Murray McGavin DD. 2003. Diabetic retinopathy: clinical findings and management. J Comm Eye Health, 16:21-4.

Williams R, Airey M, Baxter H, et al. 2004. Epidemiology of diabetic retinopathy and macular oedema: a systematic review. Eye, 18:963-83. 